\title{
Formulation and Characterization of Tapentadol Loaded Emulgel for Topical Application
}

\author{
Nitin Prabhakar Ambhore*, Panchaxari Mallapa Dandagi, Anand Panchaxari Gadad, Paresh Mandora \\ Department of Pharmaceutics, KLE University College of Pharmacy, Belagavi-590010, Karnataka, INDIA.
}

\begin{abstract}
Background: Tapentadol is a centrally acting analgesic drug which falls under class III drug as per biopharmaceutical classification systems having poor bioavailability. Aim: Therefore, present study was aimed at solubility and permeability enhancement of Tapentadol using emulsomes loaded emulgel drug delivery system. Methods: Emulgel was prepared using data light liquid paraffin, Tween 20 and PEG 400 as Surfactant and Co-surfactant respectively. For preparation of stable Emulgel, micro emulsion region was identified by constructing pseudo ternary phase diagram containing different proportion of surfactant: co-surfactant $(1: 1,2: 1$ and 3:1), oil and water. Ex vivo drug release study was done and compared to in vitro drug release of optimized formulation X2O1. PhysicoChemical Evaluation: Total nine Emulgel formulations were prepared and evaluated for self-emulsification time, dispersibility, droplet size analysis, stability studies, turbidimetry, zeta potential, drug content and in vitro and ex vivo drug release. Results: Among all the formulations, optimized formulation $\times 201$ with $1.5 \%$ carbopol 981 and optimized Q1 emulsion formulation showed in vitro drug release of $90.03 \%$ at the end of $8 \mathrm{hrs}$. Based on results of self-emulsification time \& dispersibility, droplet size analysis, drug content and in vitro drug release the $\mathrm{X} 201$ formulation was selected as an optimized formulation which showed a maximum drug release in vitro and ex vivo and extended drug release up to eight hrs. The optimized formulation found to be stable, non-irritant and safe for topical drug delivery. Conclusion: Hence emulgel formulations can be a potential alternative to traditional oral drug delivery systems of Tapentadol to improve its bioavailability.
\end{abstract}

Key words: Tapentadol, Microemulsion, Emulgel, Skin Permeation, Optimization, Topical Delivery.

\section{INTRODUCTION}

Tapentadol is a centrally acting analgesic believed to act through a dual mechanism as opioid receptor agonist and an inhibitor of norepinephrine reuptake, approved for treatment of moderate to severe pain in adults 18 years and older. It is also specifically indicated for controlling the pain of diabetic neuropathy when opioid medication is required. The short biological half-life (about $4 \mathrm{hr}$ ) and the usual oral dosage regimen is 50 to $100 \mathrm{mg}$ every 4 to $6 \mathrm{~h}$ with a maximum dosage of $600 \mathrm{mg} /$ day. It is 18 times less potent than morphine in terms of binding to human mu-opioid receptors. Tapentadol is available in the dose of $50 \mathrm{mg}, 75 \mathrm{mg}$, and $100 \mathrm{mg}$ in the form of oral tablets. Tapentadol has an oral bioavailability of $31.9 \pm 6.8 \%$, protein binding of $20 \%$ and t1/2 of 4 hrs. It is metabolized hepaticaly. ${ }^{1}$ Oral drug delivery is most desirable route of administration because of its high patient satisfactoriness, flexibility in formulation and stability. ${ }^{2}$ Factors that often impact the absorption of orally administered drugs include frequent dosing which results in fluctuation of plasma drug concentration and finally toxicity. ${ }^{3}$ The low bioavailability and very less half life the frequency of administration is more causes poor patient compliance. The low oral bioavailability and
Submission Date: 15-01-2017; Revision Date: 02-03-2017; Accepted Date: 30-03-2017

DOI: $10.5530 / \mathrm{ijper.51.4.81}$ Correspondence: Nitin Prabhakar Ambhore, Department of Pharmaceutics, KLE's College of Pharmacy, Belagavi- Karnataka, INDIA Tel.no: +91-9421118455 E-mail: nitinpatil.ambhore@ gmail.com

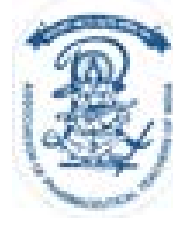

www.ijper.org 
short half life intend to go for topical route of administration.

Topical delivery can be defined as the application of drug containing formulation to skin to directly treat the cutaneous disorders or the cutaneous manifestation of general disease with the intent of confining the pharmacological or other effect of the drug to the surface of skin or within the skin. Most widely used semisolid preparations includes gel, creams, ointments etc

The USP defines gel as a semisolid system consisting The USP defines gel as a sisting of dispersions made up of either small inorganic particle or large organic molecules enclosing and interpenetrated by liquid. The gel contains larger amount of aqueous or hydro alcoholic liquid in a network of colloidal solid particles which may consist of inorganic or organic substances. Inspite of many advantage of gels a major limitation is in the delivery extended release of hydrophilic drugs. So to over this limitation an emulsion based approach is being used so that even a hydrophobic therapeutic moiety can enjoy the unique properties of gels.

When emulsions and gels are used in combined form the dosage form is referred to as "Emulgel" The presence of gelling agent in the water phase colvets the chence or gellig agent in the water phase consts the classica enu containing randomy distributed oil micro droplets.

Emulsions ate biphasic systems in which one immiscible liquid is dispersed into other due to which the system becomes unstable and so stabilized by adding emulsifying agent. Emulsion itself is a controlled release system where entrapped drug particles in internal phase passes through the external phase and then slowly gets absorbed into the skin. The gel forms a cross linked network where it captures small drug particles and provides its release in a control manner.

Emulgel are emulsions either oil-in-water or waterin-oil type which are gelled by mixing with a gelling in-oll type whe are gelling of its favo ho properties such as being thixome or its favo be properties such as being thixotropic, greaseless, casily preadable, casily removable, emollient, nonstaining, long shelf lie, bio friendly, transparent and pleasing appearance.

Microemulsions are homogeneous, transparent, thermodynamically stable dispersions of water and oil stabilized by addition of surfactant, usually in combination with co-surfactant and whose droplet size is in the range of 20-200 $\mathrm{nm}$. Since microemulsions have large surface area, they can incorporate in their core larger quantitie of molecules which are insoluble in continuous phase. The main difference between emulsion and microemulsion is the size and the shape of the droplets and

since the size of the droplets in microemulsion is much smaller than the wavelength of visible light the microemulsions are transparent. The microemulsions ar prepared with high concentration of surfactant which is useful in the greater solubilisation of drugs and also requires lesser amount of energy.

To overcome the disadvantages of Tapentadol in the oral delivery an attempt has been made in the present study to formulate emulgel of Tapentadol by incorpo-

\section{MATERIALS AND METHODS}

Tapentadol $\mathrm{HCl}$ was procured from Precises Chemipharma Pvt. Ltd, Mumbai. Light liquid paraffin was procured from S.D Fine Chem Limited Mumbai. Tween 20, PEG400, Carbopol 940 NF, Carbopol 934 NF was procured from Hi-media Pvt Ltd Mumbai. Carbopo $981 \mathrm{NF}$ was procured from Lubrizole Mumbai.

\section{Saturation Solubility of Oils, Surfactant and}

\section{Co-Surfactant}

\section{Saturation Solubility in Oils}

Excess amount of drug was added to $10 \mathrm{ml}$ vials containing $10 \mathrm{ml}$ of oils (Castor oil, sunflower oil, coconut oil and oleic acid) and then it was kept on a mechanical shaker for 72 hrs. After 72 hrs solution was centrifuged for $10 \mathrm{mins}$ at $3000 \mathrm{rpm}$ and then the supernatant was filtered and then UV absorbance was taken at $273 \mathrm{~nm}$ by suitable dilution with buffer.

\section{Saturation Solubility in Surfactants}

Excess amount of drug was added to $10 \mathrm{ml}$ of vials containing $10 \mathrm{ml}$ of surfactants (Tween 20, Tween 60 Tween 80,) and it was kept on a mechanical shaker fo $72 \mathrm{hrs}$. After 72 hrs solution was centrifuged for $10 \mathrm{~min}$ at $3000 \mathrm{rpm}$ and then the supernatant was filtered and UV absorbance was taken at $273 \mathrm{~nm}$ by suitable dilution with buffer.

\section{Saturation Solubility of Tapentadol with}

Excess amount of drug was added to $10 \mathrm{ml}$ of co-surfactant (PEG 400, PEG 600 and Propylene Glycol) and it was kept on a mechanical shaker for $72 \mathrm{hrs}$. After $72 \mathrm{hrs}$ solution was centrifuged for 10 mins at $3000 \mathrm{rpm}$ and then the supernatant was filtered and UV absorbance was taken at $273 \mathrm{~nm}$ by suitable dilution with chloroform. 89

\section{Construction of pseudoternary phase Diagrams}

Pseudoternary phase diagrams were constructed using Chemix school 3.60 software. The method used for study was water titration method. The surfactant and co-surfactant was mixed in the ratio of 1:1, 2:1 \& 3:1 keeping the co-surfactant concentration constant and varying the surfactant concentration. The surfactan and co-surfactant were mixed in a ratio and vortexed for 5 mins. Then the oil was added to surfactant and co-surfactant in the ratio ranging from 1:9 to 9:1 respectively. The water was added to the mixture drop by drop by burette and then the mixture was observed for any turbidity or gel formation. The point at which turbidity or gel formation is observed is considered as the end point of titration. The data obtained was feed in the Chemix School 3.60 software to obtain the area emulsification. ${ }^{10}$

\section{Preparation of Emulsion}

Water titration method was employed for the preparation of microemulsion. The concentrations of oil, water, surfactant and cosurfactant were varied in each case keeping the concentration of drug constant and dish cased in Table 1. Predeterming a nount of drug displayed in Table 1. Predety weighed and dissoled in

Surfactart and co-sufferantwere added to oily solvion of the drug and mechanically stirred (Magnetic stirret) form an enulion. Water was alded dop wise to emulion ill the form was acd a drop wise to the Formion of thasparion of a transparent mixture. of microemulsion.

\section{Evaluation of Prepared Microemulsion}

\section{Drug Content of Emulsion}

$1 \mathrm{ml}$ of emulsion was taken and it was added to $10 \mathrm{~m}$ volumetric flask and then the volume was made with chloroform and then further dilutions were made and UV absorbance was taken at $273 \mathrm{~nm}$. The blank was prepared by preparing microemulsion without drug and then $1 \mathrm{ml}$ from that was taken and it was added to $10 \mathrm{~m}$ volumetric flask and serial dilutions were made with chloroform and then the UV readings were taken, the values obtained was used to calculate the concentratio of drug in emulsion.

\section{Globule Size Determinatio}

The globule size distribution of the formulations was measured by Dynamic Light Scattering Particle Size Analyzer (Nanotrac Particle Size Analyzer). The range of the analyzer is $0.02 \mathrm{~nm}$ to $2.8 \mu \mathrm{m}$. $01 \mathrm{ml}$ of the emulsion was taken and it was diluted to $250 \mathrm{ml}$ with distilled water and then the readings were taken.

\section{Zeta Potentia}

The zeta potential is defined as the difference in potential plane) and the electro-neutral region of the solution. Zeta potential was measured by using Zeta meter instrument.

The gel base was prepared by soaking the gelling agent overnight in a sufficient quantity of water and then th emulsion equivalent to $0.5 \%$ was incorporated in the ge base to give emulgel. The different batches of emulge were prepared according to the formulation chart given in Table 2 and 3.

\section{Characterisation of Emulgel}

\section{Physical Examination}

The prepared Emulgel formulations were inspected visually for their color, homogeneity and consistency.

\section{Drug Content}

$1 \mathrm{gm}$ of emulgel was accurately weighed and it was dissolved in $100 \mathrm{ml}$ of chloroform and it was kept fo sonication for 2 hrs. The solution was passed through filter paper and filtered. The absorbance was measured ectrophotometrically at 273 mm against corresponding Emulgel without drug as blat. Drug content a linear ele using the slope and the intercept obtained by Experiments were carried out in triplicates.

$\mathrm{pH}$

The $\mathrm{pH}$ of various emulgel formulations were determined by using digital $\mathrm{pH}$ meter.

$1 \mathrm{~g}$. of emulgel was dissolved in $100 \mathrm{ml}$ distilled water and stored for $2 \mathrm{hrs}$. The measurement of $\mathrm{pH}$ of each formulation was done in triplicate.

\section{iscosity}

The measurement of viscosity of the prepared emulge was done with a Brookfield Rheometer. The emulge was rotated at $1 \mathrm{rpm}$ and the corresponding dial reading was noted. The viscosity of the gel was obtained by that reading. The viscosity was measured in $\mathrm{cps}$.

\section{Spreadability}

It indicates the extent of area to which emulgel readily spreads on application to skin or affected part the uppe slide was noted down. A weighed quantity $(350 \mathrm{mg})$ of emulgel was taken on a glass plate $(10 \times 5 \mathrm{~cm})$. Another glass plate $(10 \times 5 \mathrm{~cm}$ and $5.8 \pm 1 \mathrm{~g})$ was dropped from distance of $5 \mathrm{~cm}$. The diameter of the circle of spread was measured after 1 min. ${ }^{11}$

\section{Extrudability}

Extrudability test is based upon the determination of weight required to extrude $0.5 \mathrm{~cm}$ ribbon of emulgel in 
Table 1: Formulation Table of Tapentadol Emulsion

\begin{tabular}{|c|c|c|c|c|c|c|c|}
\hline Sr no. & $\begin{array}{c}\text { Formulation } \\
\text { code }\end{array}$ & $\begin{array}{c}\text { S: Cos } \\
\left.\text { ratio[ } \text { six }_{\text {mix }}\right]\end{array}$ & $\begin{array}{c}\text { Oil: Smix } \\
\text { ratio }\end{array}$ & $\begin{array}{c}\text { Amount } \\
\text { of drug } \\
\text { added (mg) }\end{array}$ & $\begin{array}{c}\text { Approx Theoretical } \\
\text { drug content(mg) }\end{array}$ & $\begin{array}{c}\text { Total volume of } \\
\text { mixture (ml) }\end{array}$ & $\begin{array}{c}\text { Amount of } \\
\text { water (ml) }\end{array}$ \\
\hline 1 & P1 & $1: 1$ & $1: 9$ & 250 & 230.209 & 10 & 0.6 \\
\hline 2 & P2 & $1: 1$ & $2: 8$ & 250 & 200.350 & 10 & 0.4 \\
\hline 3 & P3 & $1: 1$ & $3: 7$ & 250 & 190.000 & 10 & 0.5 \\
\hline 4 & Q1 & $2: 1$ & $1: 9$ & 250 & 226.430 & 10 & 0.6 \\
\hline 5 & Q2 & $2: 1$ & $2: 8$ & 250 & 217.703 & 10 & 0.4 \\
\hline 6 & Q3 & $2: 1$ & $3: 7$ & 250 & 205.37 & 10 & 0.5 \\
\hline 7 & R1 & $3: 1$ & $1: 9$ & 250 & 213.90 & 10 & 0.6 \\
\hline 8 & R2 & $3: 1$ & $2: 8$ & 250 & 211.035 & 10 & 0.5 \\
\hline 9 & R3 & $3: 1$ & $1: 9$ & 250 & 207.50 & 10 & 0.3 \\
\hline
\end{tabular}

*Data are expressed as Mean \pm S.D. $(n=3)$

\begin{tabular}{|c|c|c|c|c|c|c|}
\hline INGREDIENTS & X1P1 & $\mathrm{X} 2 \mathrm{Q} 1$ & Y1P1 & Y2Q1 & Z1P1 & $\mathrm{Z2Q} 1$ \\
\hline Tapentadol emulsion & $0.25 \%$ & $0.25 \%$ & $0.25 \%$ & $0.25 \%$ & $0.25 \%$ & $0.25 \%$ \\
\hline $\begin{array}{l}\text { equivalent to } 0.25 \% \\
\text { Carbopol } 981\end{array}$ & $1.5 \%$ & $1.5 \%$ & & & & \\
\hline $\begin{array}{l}\text { Carbopol } 934 \\
\text { Carbopol } 940\end{array}$ & & & $1.5 \%$ & $1.5 \%$ & $1.5 \%$ & $1.5 \%$ \\
\hline & & & & & & \\
\hline 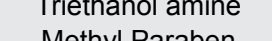 & $1 \%$ & $1 \%$ & $1 \%$ & $1 \%$ & $1 \%$ & $1 \%$ \\
\hline Mentny Paraben & $0.02 \%$ & & $0.02 \%$ & $0.02 \%$ & $0.02 \%$ & $0.02 \%$ \\
\hline & 0.0070 & 0.0020 & 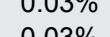 & $0.03 \%$ & $0.03 \%$ & $0.03 \%$ \\
\hline Distilled water q.s & $\begin{array}{c}.03 \% \% \\
100\end{array}$ & $\begin{array}{l}0.03 \% \\
100\end{array}$ & $\begin{array}{c}.03 \% \% \\
100\end{array}$ & $\begin{array}{c}0.03 \% \\
100\end{array}$ & $\begin{array}{l}.03 \% \\
100\end{array}$ & $\begin{array}{l}0.03 \% \\
100\end{array}$ \\
\hline
\end{tabular}

Data are expressed as Mean \pm S.D. $(n=3)$

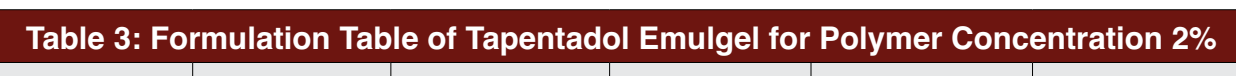

\begin{tabular}{|c|c|c|c|c|c|c|}
\hline INGREDIENTS & $X^{\prime} 1 P 1$ & $X^{\prime} 2 Q_{1}$ & $Y^{\prime} 1 P 1$ & $Y^{\prime} 2 Q 1$ & $Z^{\prime} 1 P 1$ & $Z^{\prime 2} 2 \mathbf{P}^{\prime}$ \\
\hline $\begin{array}{l}\text { Tapentadol emulsion } \\
\text { equivalent to } 0.25 \%\end{array}$ & $0.25 \%$ & $0.25 \%$ & $0.25 \%$ & $0.25 \%$ & $0.25 \%$ & $0.25 \%$ \\
\hline Carbopol 981 & $2 \%$ & $2 \%$ & & & & \\
\hline Carbopol 934 & & & $2 \%$ & $2 \%$ & & \\
\hline Carbopol 940 & & & & & $2 \%$ & $2 \%$ \\
\hline Glycerin & $1 \%$ & $1 \%$ & $1 \%$ & $1 \%$ & $1 \%$ & $1 \%$ \\
\hline Triethanol amine & $0.02 \%$ & $0.02 \%$ & $0.02 \%$ & $0.02 \%$ & $0.02 \%$ & $0.02 \%$ \\
\hline Methyl Paraben & $0.03 \%$ & $0.03 \%$ & $0.03 \%$ & $0.03 \%$ & $0.03 \%$ & $0.03 \%$ \\
\hline Propyl Paraben & $0.03 \%$ & $0.03 \%$ & $0.03 \%$ & $0.03 \%$ & $0.03 \%$ & $0.03 \%$ \\
\hline Distilled water q.s & 100 & 100 & 100 & 100 & 100 & 100 \\
\hline
\end{tabular}

Data are expressed as Mean $+S . D$. (n=3)

$10 \mathrm{sec}$ from lacquered collapsible aluminium tube. The test was performed in triplicate and the average value

were calculated. The extrudability was then calculated

by using the following formula. ${ }^{12}$

$$
\text { Weight applied to extrude }
$$

Extrudability $=\frac{\text { emulgel from tube (in g) }}{\operatorname{sren}_{\left(\mathrm{in}^{2} \mathrm{~cm}^{2}\right)}}$ membrane. $50 \mathrm{ml}$ of the Phosphate buffer of $\mathrm{pH} 6.8$ was used as dissolution media which was added to the receptor compartment. The donor compartment was kept in contact with receptor compartment. This whole assembly was kept on a magnetic stirrer and the solution on the receptor side was stirred continuously using a magnetic bead and temperature of the cell was maintained at $37 \pm 0.5^{\circ}$ Sample $(1 \mathrm{ml})$ was withdrawn at suitable time intervals and replaced with the equal amounts of fresh dissolution media. Samples were analyzed spectrophotometrically at $273 \mathrm{~nm}$ and the cumulative $\%$ drug release was calculated. The oraph is plotted of $\%$ cumulative drug releases versus time.

\section{Ex Vivo Drug Diffusion}

The abdominal skin of full thickness was excised from the rats weighing 105-120 g, free from any visible sign of diseases. This was mounted in the donor compargn of The emulgel was phaced over it and the peration

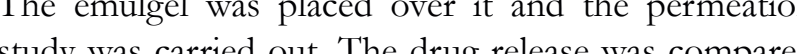
with that of optimize Thulation.

\section{Skin Irritation Test}

The skin irritation test was performed on the male wistar ats. The anits were difide ie. control, standert and test. The back shin of the rat of $5 \mathrm{~cm}^{2}$ was shaven one day pror to the stang of the study After 24 hrs of shing the skin of tan is the stan was applied with $0 . \% \%$ of saline which with the optinis for the test group was applied observed for any irritation at the end of 24hrs the animals were observed for any skin irritation like erythem or edema and score were given accordingly.

\section{Stability Studies}

Short term stability study was performed on the optmized formulation. The formulation was subjected to different conditions of temperature and relative humidity i.e. $25^{\circ} \mathrm{C} / 60 \% \mathrm{RH}$ and $40^{\circ} \mathrm{C} / 65 \% \mathrm{RH}$ for a period of 2 months. Samples were withdrawn at the interval of 1 month and were evaluated for rheological properties, drug content. ${ }^{14}$

\section{RESULTS AND DISCUSSION}

\section{Saturation Solubility in Oils, Surfactant and}

Co-Surfactant

The various oils used for study were oleic acid, coconut oil, castor oil and sunflower oil, light liquid paraffin. The solubility in light liquid paraffin was found to be $3 \mathrm{mg} / \mathrm{ml}$ that was the maximum solubility compared to other oils. The graphical representation is chown in Figure 1 . The observed for and formulation $\mathrm{X} 2 \mathrm{Q} 1$ and the rats were

different type of surfactants used for solubility studies were Tween 20, Tween 60, Tween 80, Span 20, Span 80 and co-surfactants used were PEG 400, PEG 600 and Propylene glycol. The maximum solubility among surfactants were found in case of Tween 20 i.e. $10 \mathrm{mg} / \mathrm{m}$ and in case of co-surfactants is of PEG400 i.e. $15 \mathrm{mg} / \mathrm{ml}$ the results of the solubility of surfactant and its graphical representation was shown in Figure 2 and 3. So based on the solubility light liquid paraffin (oil), Tween 20 (surfactant) and PEG 400(co-surfactant) were selected for the preparation of emulsion.

\section{Construction of Pseudoternary Phase Diagram}

The construction of phase diagrams makes it easy to find out the concentration range of components fo existence range of microemulsions. The selected oil, surfactant and co-surfactant based on solubility studies were used to construct the phase diagrams. The method

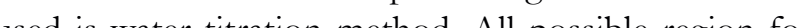
emulion forma iot possible emulsion formation at all possible ratios of suffactan: co-surfact study the oil, surfactant and co-surfactant having highest solubility were selected and then for the construction of pseudoternary phase diagram construction the ratio of co-surfactant was kept constant but the ratio of surfactant was varied from 1:1, 2:1 and 3:1. The oil was added to each ratio of surfactant: co-surfactan (Smix) in varying quantities from 1:9 to 9:1. The wate was added drop wise through burette till turbidity was observed. The microemulsion region in the phase diagram is the region where clear and transparen formulation was produced shown in Figure 4.

The region shaded purple in the phase diagrams were considered as the microemulsion region as shown in the Figure 5 . The rest phase diagram region correspond to turbid and conventional emulsion systems. The effect of water concentration on the area of isotropic regions was evident in the given phase diagpossibly because Tween 20 is a non-ionic solvent that forms clear solution in water, so the area of $\mathrm{O} / \mathrm{W}$ microemulsion was increased. The largest microemulsion region wa obtained for the surfactant: co-surfactant ratio of $3: 1$ and smallest microemulsion area was obtained for the ratio 1:1. And it was observed that as the concentration of surfactant increases the quantity of water required to obtain turbidity also increases and as more the wate quantity required the solubility of drug also decreases. It was observed that as the concentration of oil and Smix ratio increases from 1:9 to 9:1 the stability decreases as phase separation occurs on storage. So on the basis of stability the just first three ratios of oil: Smix was buffer of $\mathrm{pH} 6.8$ for 9-12 $\mathrm{h}$ and was clamped carefully between the donor and receptor compartment. Then 
The area of microemulsion increased as the concentration of surfactant increases.

\section{Formulation of Emulsion}

The mixture of surfactant: co-surfactant (Smix) and oil was prepared by adding the quantities obtained from pseudoternary phase diagrams. The $250 \mathrm{mg}$ of drug was added to the formulation based on its solubility in surfactant, co-surfactant and oil. The mixture was kept for stirring on magnetic stirrer till the drug completely solubilizes and then it was kept for $24 \mathrm{hrs}$ to atain the

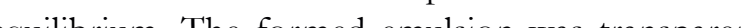
ansparent in

The formulation P1, P2, P3 contains the surfactant cosurfactant ratio 1:1 and the oil: Smix ratio was varied from 1:9 to 3:7 same way in Q1, Q2, Q3 contains the surfactant: Co-surfactant ratio 2:1 and oil: Smix ratio 1:9 to $3: 7$ and in the formulation R1, R2, R3 contains the surfactant: co-surfactant ratio of 3:1 and oil: Smix ratio same as in case of above formulations. The prepared emulsions were then evaluated for drug content and droplet size.

\section{Evaluation of Prepared Microemulsion}

Drug Content

The percentage drug content of all the nine formulations of Tapentadol emulsion was determined and the percentage of drug present was showed in the Table 4 The drug content varied from $78 \%$ to $95 \%$. The formulation Q1 has drug content of $95.13 \%$ and that of $\mathrm{P} 1$ was $94.01 \%$ and of R1 was $92.97 \%$. The highest drug content was found in case of Q1 formulation due to greater solubilisation of drug as compared to others and even as the quantity of water required to formed the microemulsion was less in case of $1: 1$ ratio of surfactant: co-surfactant, 1:9 ratio of oil: Smix.

\section{Globule Size Determination}

The globule size of all the prepared microemulsion wa evaluated using nanotrac. The particle size obtained was reported in Table 4. On the basis of result obtained it was found that the globule size decrease as the concentration of surfactant increased. The globule size of the formulations P1 and Q1 was found to be 176 and $116 \mathrm{~nm}$ respectively. The formulation $\mathrm{P} 1$ and $\mathrm{Q} 1$ was selected a optimized microemulsion formulation based on globule size as it was ranging in microemulsion region and there was not much difference in the drug content of the two formulations. The formulation R1 had highest globular size compared to formulation P1 so it was not selected as increase in olobular size delays diffusion rate.

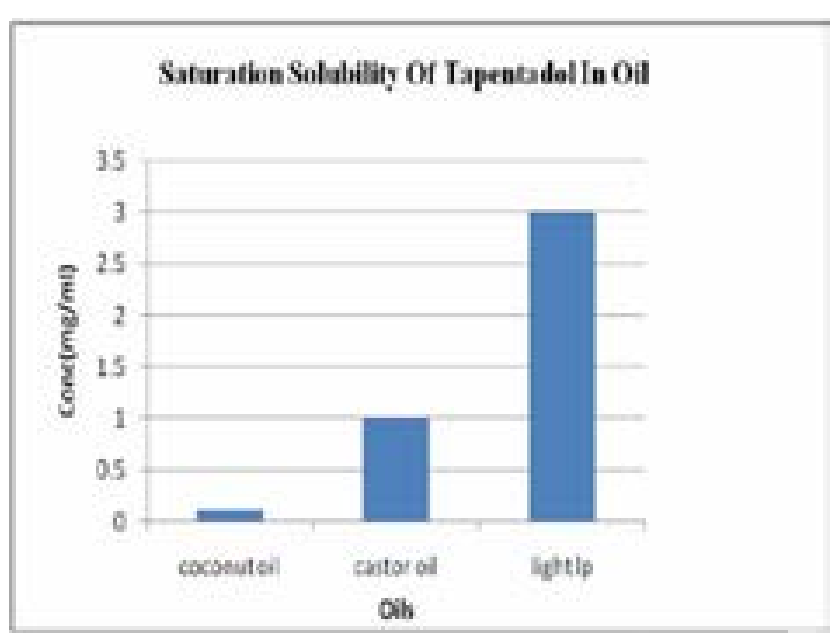

Figure 1: Saturation solubility of tapentadol in oils.

\section{Saturation Solubilitity of Tapentadel In Surfactant}

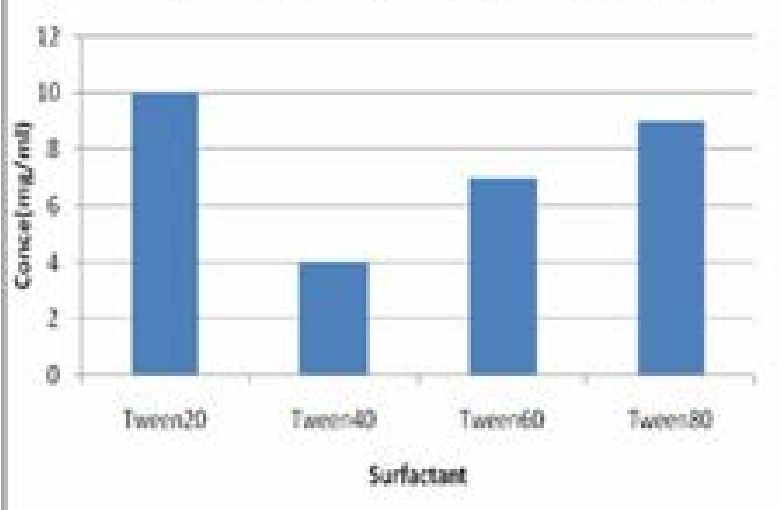

Figure 2: Saturation solubility of tapentadol in surfactant.

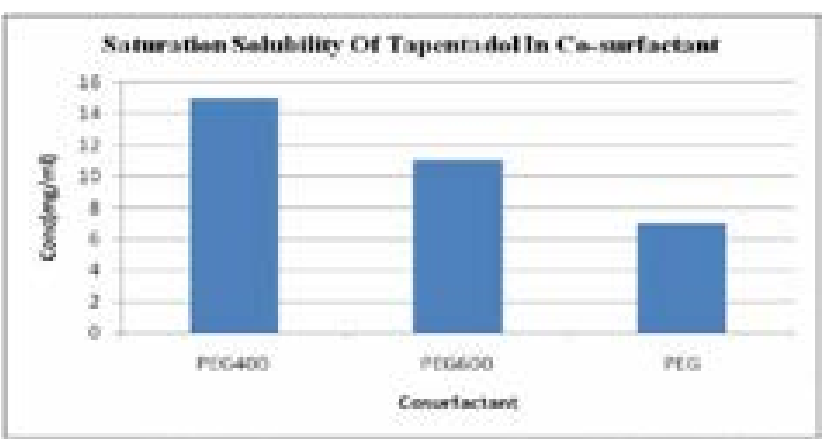

Figure 3: Saturation solubility of tapentadol in cosurfactant.

So based on globule size and drug content the formulations P1 and Q1 were selected as optimized formulation for further studies.

\section{Zeta Potential Determination}

The Zeta potential of all formulations was found to be in the range of -28.08 to-59.513 and it's displayed in given Table 4 . The zeta potential showed that the formulations showed moderate to good stability.

\section{Preparation of Emulgel}

Emulgel was prepared using different gelling agent such as carbopol 934, carbopol 940 and carbopol 981 in the concentration of $1.5 \% \mathrm{w} / \mathrm{v}$ and $2 \% \mathrm{w} / \mathrm{v}$ The mention gelling agents were swelled in distilled water for $24 \mathrm{hrs}$ and high viscosity solution was obtained. The Taper lo micosm son loaded microenulsion was slowly added to the viscous solution of gelling agent by conthuous stirning and then clear emulgel was obtained. The carbopol as an aqueous gel matrix is a continuous phase and the dispersion of oily droplets within the meshes of 3-D network of ge increases the viscosity of microemulsion significantly. The optimized formulations of microemulsions i.e. PI and Q1 was incorporated into the gel base The quantity of microemulsion added was equivalent to $0.25 \%$ of Tapentadol, $0.02 \%$ of triethanolamine was added to adjust the $\mathrm{pH}$ of formed emulgel, glycerin $1 \%$ and the preservatives like methyl Paraben and Propyl Paraben was added to the formulation, the quantity of preservative added was $0.03 \%$ showed in Table $2 \& 3$.

\section{Characterisation of Emulgel}

\section{Physical Appearance}

All the prepared formulations were buff white in appearance and they showed good homogeneity and consistency.

\section{Drug Content}

The percentage drug content of prepared emulgel was found in the range of 74.6 to $96.253 \%$. The results were displayed in the Table 5. The highest drug content i.e. $96.253 \%$ was obtained for the formulation X2Q1 containg optimized Q1 formulation of emulsion and gelling agent present in the concentration of $1.5 \%$ of Carbopol 981.

$\mathrm{pH}$

The $\mathrm{pH}$ of all the formulation was found to be ranging from 5.5to 6.53 which was found to be acceptable to avoid any skin irritation. The results in the form of Table are shown in the Table 5.

\section{Viscosity}

Viscosities of different Tapentadol emulgel formulations re shown in Table 6 . The viscosity ranged between 11970 to $48229 \mathrm{cPs}$. The results showed that the emulgel formulations prepared by using carbopol 940 showed higher viscosity as compared to that of the others. The viscosity is represented graphically in the Figure 6 The low viscosity was found for the X2Q1 formulation containing the low concentration i.e. $1.5 \%$ of carbopol 981 polymer which is a low viscosity polymer and the addition of microemulsion Q1. It was found that as polymer concentration increases viscosity also increases. The Q1 microemulsion formulation it contains the larger amount of surfactant concentration as compared to the P1 so its viscosity decreases as mentioned by Ghodekar et al in his work antifungal activity of microemulsion based fluconazole gel for so the viscosity of emulgel containing the optimized formulation Q1 and carbopol 981 concentration $1.5 \%$ was found to be the lowest i.e. $\mathrm{X} 2 \mathrm{Q} 1$ formulation as compared to the formution containing option as formut P1 and cabopol 981 concentized $1.5 \%$. The highe he concen

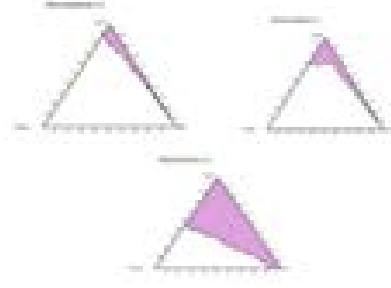

Figure 4: Pseudoternary phase diagrams of surfactant: co-surfactant ratios 1:1, 2:1, and 3:1.

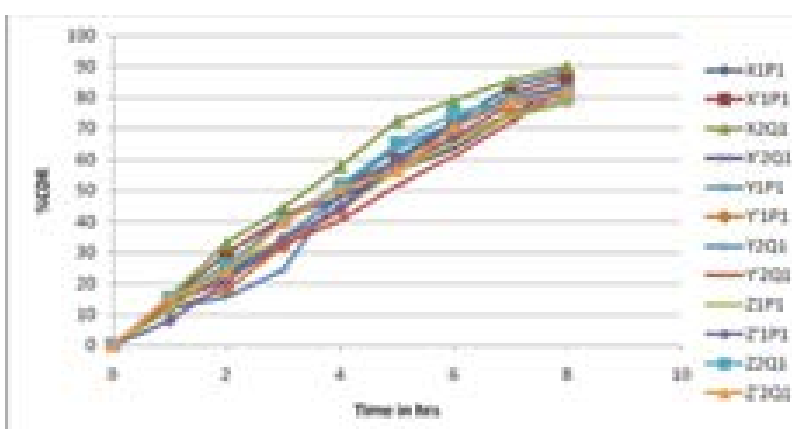

Figure 5: In vitro release profile.

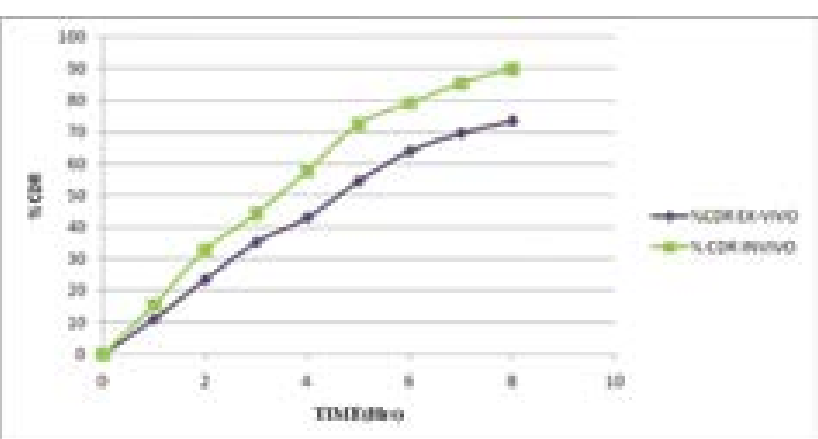

Figure 6: Comparison of ex vitro and In vitro cumulative release of optimized formulation. 
Table 4: Drug Content, Globule Size And Zeta Potential of Emulsion Formulations

\begin{tabular}{|c|c|c|c|}
\hline Formulation code & Globular size & Drug Content & Zeta Potential* $^{*}$ \\
\hline P1 & $176.8 \mathrm{~nm}$ & $94.01 \pm 6.023$ & $-49.79 \pm 2.74$ \\
\hline P2 & $399 \mathrm{~nm}$ & $90.12 \pm 0.77$ & $-43.03 \pm 2.34$ \\
\hline P3 & $504 \mathrm{~nm}$ & $81.00 \pm 0.65$ & $-38.34 \pm 3.69$ \\
\hline Q1 & $116 \mathrm{~nm}$ & $95.13 \pm 5.074$ & $-59.513 \pm 1.80$ \\
\hline Q2 & $338 \mathrm{~nm}$ & $91.00 \pm 3.00$ & $-50.04 \pm 3.20$ \\
\hline Q3 & $454 \mathrm{~nm}$ & $80.06 \pm 1.012$ & $-47.33 \pm 1.43$ \\
\hline R1 & $199.5 \mathrm{~nm}$ & $92.97 \pm 4.098$ & $-35.08 \pm 4.13$ \\
\hline R2 & $202.4 \mathrm{~nm}$ & $89.00 \pm 8.001$ & $-28.08 \pm 2.13$ \\
\hline R3 & $347 \mathrm{~nm}$ & $78.00 \pm 1.198$ & $-36.56 \pm 2.99$ \\
\hline
\end{tabular}

Data are expressed as Mean \pm S.D. $(n=$

\begin{tabular}{|c|c|c|c|}
\hline \multicolumn{5}{|c|}{ Table 5: Appearance, Drug Content, Ph of Emulgel Containing Carbopol 981, Carbopol 934 and Carbopol } \\
\hline Formulation Code & Color & Drug Content & $\mathbf{p H}^{*}$ \\
\hline X1P1 (carbopol 981 1.5\%) & Buff White & $94.513 \pm 0.82$ & $6.14 \pm 0.065$ \\
\hline X2Q1 (carbopol 981 1.5\%) & Buff White & $96.253 \pm 1.09$ & $5.58 \pm 0.0124$ \\
\hline Y1P1 (carbopol 934 1.5\%) & Buff White & $90.093 \pm 0.81$ & $6 \pm 0.0081$ \\
\hline Y2Q1 (carbopol 934 1.5\%) & Buff White & $91.763 \pm 0.68$ & $5.5 \pm 0.014$ \\
\hline Z1P1 (carbopol 940 1.5\%) & Buff White & $82.806 \pm 1.09$ & $6.35 \pm 0.041$ \\
\hline Z2Q1 (carbopol 940 1.5\%) & Buff White & $85.81 \pm 6.97$ & $6.3 \pm 0.07$ \\
\hline X'1P1 (carbopol 981 2\%) & Buff White & $89.116 \pm 7.45$ & $6.12 \pm 0.052$ \\
\hline X'2Q1 (carbopol 981 2\%) & Buff White & $93.86 \pm 7.50$ & $5.51 \pm 0.379$ \\
\hline Y'1P1 (carbopol 934 2\%) & Buff White & $77.5633 \pm 4.17$ & $6.03 \pm 0.131$ \\
\hline Y'2Q1 (carbopol 934 2\%) & Buff White & $84.656 \pm 4.87$ & $5.79 \pm 0.1925$ \\
\hline Z'1P1 (carbopol 940 2\%) & Buff White & $75.616 \pm 0.77$ & $6.35 \pm 0.313$ \\
\hline Z'2Q1 (carbopol 940 2\%) & Buff White & $74.6 \pm 0.60$ & $6.12 \pm 0.0817$ \\
\hline
\end{tabular}

Data

\begin{tabular}{|c|c|c|c|}
\hline Formulation Code & $\begin{array}{l}\text { Viscosity* } \\
\text { (cPs) }\end{array}$ & $\begin{array}{c}\begin{array}{c}\text { Spreadability* } \\
\text { sec) }\end{array}\end{array}$ & Extrudality * $\left(\mathrm{gm} / \mathrm{cm}^{2}\right)$ \\
\hline X1P1 (carbopol 981 1.5\%) & $11930 \pm 122.6943$ & $3.83 \pm 0.047$ & $12.74333 \pm 0.744$ \\
\hline X2Q1 (carbopol $9811.5 \%$ ) & $11970 \pm 60.82$ & $3.9 \pm 00$ & $14.82667 \pm 0.600$ \\
\hline Y1P1 (carbopol $9341.5 \%$ ) & $37531.67 \pm 612.58$ & $3.4 \pm 0.0942$ & $6.63 \pm 0.497$ \\
\hline Y2Q1 (carbopol $9341.5 \%$ ) & $36409.67 \pm 4114$ & $3.66 \pm 0.047$ & $6.116667 \pm 1.017$ \\
\hline Z1P1 (carbopol 9401.5 \%) & $41834 \pm 1489$ & $3.43 \pm 0.047$ & $2.673333 \pm 0.253$ \\
\hline Z2Q1 (carbopol $9401.5 \%$ ) & $42570 \pm 192$ & $3.5 \pm 0.081$ & $4.573333 \pm 0.489$ \\
\hline X1'P1 (carbopol $9812 \%$ ) & $17993.67 \pm 440$ & $2.13 \pm 0.04$ & $9.036667 \pm 0.925$ \\
\hline X2'Q1 (carbopol 9812 \%) & $20550 \pm 505.742$ & $2.3 \pm 0.08$ & $10.31 \pm 1.070$ \\
\hline Y1'P1 (carbopol 9342 \%) & $39237 \pm 659.568$ & $2.2 \pm 00$ & $5.006667 \pm 0.601$ \\
\hline Y2'Q1 (carbopol $9342 \%$ ) & $38829.33 \pm 180.003$ & $2.3 \pm 0.124$ & $5.476667 \pm 0.513$ \\
\hline Z1'P1 (carbopol $9402 \%$ ) & $48229.33 \pm 910.220$ & $2.03 \pm 0.047$ & $1.65 \pm 0.563$ \\
\hline Z2'Q1 (carbopol $9402 \%$ ) & $45913.67 \pm 640.1712$ & $2.3 \pm 0.816$ & $2.396667 \pm 0.2950$ \\
\hline
\end{tabular}

lower the concentration of gelling agent lower the viscosity.

\section{Spreadability}

Spreadability is the term expressed to denote the extent of area to which the emulgel spreads on application to skin or affected part. The therapeutic efficacy of formulation depends upon its spreading value. The spreadability value ranged from 2.0 to 3.9 as shown in Table 6 . The spreadability is dependent on the viscosity of formulation. The formulation X1P1 having viscosity 11970 has high spreading coefficient of $3.9 \mathrm{gm} . \mathrm{cm} / \mathrm{sec}$. The spreadability depends on the concentration of polymer and its viscosity. The emulgel with low concentration of gelling agent i. $1.5 \%$ carbopol 981 showed increase in spreadability value.

\section{Extrudability}

The extrudability gives the extent to which a semisolid formulation is extruded out from the tube. The extrudability depends on the viscosity and consisency of formulation. The less the viscosity the more the extent formulation. The less the viscosity the more the extent to which the formulation is extryded out. The extrudability of formutions ranged from 1.2 to 14.8 as shown in the Table 6 . The formulation X2Q1 has high extrudability value of $14.8 \mathrm{gm} / \mathrm{cm}^{2}$ as the viscosity of the formulation was $11790 \mathrm{cPs}$ and the least extrudability of $1.99 \mathrm{gm} / \mathrm{cm}^{2}$ was found in the case of formulation Z'1P1having viscosity of $48229 \mathrm{cps}^{15}$

\section{In vitro drug Release}

The diffusion study was carried out using Franz diffusion cell. The diffusion was carried out in $50 \mathrm{~m}$ of $\mathrm{pH} 6.8$ phosphate buffer maintained at $37 \pm 0.5^{\circ} \mathrm{C}$ and it was stirred at a constant speed using a magnetic bead on a magnetic stirrer. The percentage cumulative drug release of all the prepared emulgel formulations ranged from $77.73 \%$ to $89.998 \%$ at the end of 8 hrs. The percent cumulative drug release of the emulgel formulations are represented graphically in the Figure 5. Maximum drug release was observed in formulation $\mathrm{X} 2 \mathrm{Q} 1 \mathrm{after} 8 \mathrm{hrs}$. The reason attributed for a higher release is the lower concentration of gelling agent ie. $1.5 \%$ of carbopol 981 employed in that formulation and the concentration of the optimized micration and formula 1 1 wish formulation $Q 1$ which contains 2.1 ratio of surfactan and co-surfactant as the relcase of drug from microemulsion may be more because of the langer concentration of surfactant and even it has lower droplet size as the release rate is inversely related to particle size i.e. smaller the droplet size higher the release. ${ }^{16}$

Ex Vivo Skin Permeation Study

Indian Journal of Pharmaceutical Education and Research | Vol 51 | Issue 4 | Oct-Dec, 2017
Ex vivo skin permeation study of optimized formulation (X2Q1) was carried out using the skin of male wistar rat in Franz diffusion cell showed in Figure 6. The diffusion was carried out in $50 \mathrm{ml}$ of ph 6.8 phosphate buffer maintained at $37^{\circ} \mathrm{C} \pm 0.5^{\circ} \mathrm{C}$. The maximum percentage cumulative drug release at the end of $8 \mathrm{~h}$ was found to be $73.14 \% 28$ and was compared with optimized formulation X2Q1 showed in Figure 6. ${ }^{17}$

Skin Irritation Test

The Wistar Rats were used for the skin irritation test. The control group was not applied with any formulation, the standard group was applied with the saline $(0.9 \% \mathrm{w} / \mathrm{v})$ a standard irritant and the test group was applied with the optimized formulation X2Q1 and it was observed for irritation at the end of $24 \mathrm{hts}$. In case of standard group there was moderate erythema with barely precipitable edema and score given to it was 2 and the test group showed no inritation. Since no iritations persist the optimized formulation passes the skin irritation test.

\section{Stability Studies}

The Optimized Formulation X2Q1 showed no change in appearance after 60 days of storage. Slight increased in $\mathrm{pH}$ after 30 and 60 days was noticed. The $\mathrm{pH}$ of the formulation increased slightly after 30 and 60 days. This can be attributed to concurrence of drug and polymer ove a long period. The values of viscosity showed little alteration. Minor decrease was observed in the drug release over a period of 60 days when stored at room temperature and $40^{\circ} \mathrm{C} / 75 \%$ RH. Hence, it can be concluded that the formulation X2Q1 exhibited acceptable stability profile at room temperature $\left(25 \pm 2^{\circ} \mathrm{C}\right)$ for a period of two months and at $40^{\circ} \mathrm{C} / 75 \% \mathrm{RH}$ for a period of one months. ${ }^{19}$

In this study an attempt was made to formulate emulgel of Tapentadol for Topical delivery. DSC thermograms revealed that there was no interaction between polymer and the drug, hence, they were compatible. Based on saturation solubility study Light liquid paraffin, Tween 20 and PEG 400 were selected for the preparation of emulsion. The pseudoternary phase diagram constructed with surfactant: co-surfactant ratio of 1:1 showed the least microemulsion area and that with 3:1 ratio showed the maximum microemulsion area. Based on the globule size and drug content two optimized formulation were selected for incorporation into gel base i.e. P1 and Q1. The emulgel formulations were prepared with carbopol as gelling agent with concentrations of $1.5 \%$ and $2 \%$ and the optimized emulsion formulations i.e. P1 and Q1 we formulation 
$\mathrm{X} 2 \mathrm{Q} 1$ was found to be the optimized based on viscosity, drug content and percentage cumulative drug release. The skin irritation test on optimized formulation
showed no signs of irritation. Ex vivo drug diffusion study was conducted and was compared with optimized formulation Stability study carried out for two month revealed that the formulations were stable at room temperature and at $40^{\circ} \mathrm{C}$. Thus, it can be concluded that Tapentadol was proven to be a suitable candidate for formulating emulgel for topical delivery to achieve better patient compliance.

\section{CONCLUSION}

Self-emulsifying drug delivery system of Tapentadol was successfully prepared and evaluated for its solubility enhancement purpose. Based on solubility study data light liquid paraffin, Tween 20 and PEG 400 data light liced per construction of pseudo ternaty phase selected for constre diagram. From phase diagram, nine formulations were prepared and evaluated for self-emulsification time and dispersibility, droplet size analysis, stability studies, turbidimetry, zeta potential, drug content and in vitro drug release. Optimized formulation of emulgel showed a significant increase in drug release rate in vitro and ex vivo. Hence, it can be concluded that the emulgel formulations can be potentially used as an alternative to the traditional oral formulations for the poorly bioavailable and having short half-life drugs like Tapentadol to improve its drug penetration and bioavailability.

\section{ACKNOWLEDGEMENT}

The authors express deep gratitude to Precises Chem Pharma Ltd., Mumbai, for providing the gift sample of the drug Tapentadol. The authors are also immensely grateful to KLES College of Pharmacy, Belagavi for providing all the facilities required to carry out the research work

\section{FINANCIAL SUPPORT AND SPONSORSHIP}

\section{CONFLICT OF INTEREST}

There are no conflicts of interest.

\section{ABBREVIATION USED}

PEG: Polyethylene glycol; PG: Propylene glycol; RH 位e humidity; DSC: Differential Scanning Calorim-

\section{REFERENCES}

Kumar SS, Rao R, Jayaveera KN. Formulation development, in-vitro and
in-vivo evaluationo of Tapentadool HCI controlled release matrix tablets using

Nakagawa T, Kondo $S$, Sasai $Y$ et al. Preparation of floating drug delivery
system by plasma technique. Chem Pharm Bull. 2006;54(4):514-8. https:

doi.org/10.1248/cpb.54.514; PMid:16595955.
Pawar VK, Kansal S, Garg G et al. Gastroretentive dosage forms: A review with special emphasis on floating drug delivery systems. Drug
Deliv. 2011:18(2):97-110. https://doio.rgf/10.3109/10717544.2010.520354 Dellv. 2015;182,

San AK, Jain SK, Pandey RS. Microemulsion based hydrogel formulation of 2011;:4(4): $140-5$

Sonaje SP, Gondkar BS, Saudagar BR. Gellified Emulsion: A New Born Formulation for Topical Dest
Pharm Sci. 2013;3:233-51.

Joshi B, Singh G, Rana AC et al. Emulgel: A comprehensive Review on the Recent Advances in Topical Drug Delivery. Int Res J of Pharm. 2011;2(11):66-70 Methoxsalen for the effective treatment of p psoriasis. Asian J Pharm Clin Res 2011:4(4):140-5.

Pajapatil SK. Novel nanoemulsion as venicles for transdermal delivery or

Abd-allah FI Dito and i iv vivo studies, Int J Pharm Pharm Sci. 2013;5:126-34 based formulation to improvev the availability of poorly wate-soluble drue Drug Discov Ther. 2010;4(4):257-66. PMid:22491208.

Kaur LP, Guleri TK. Topical Gel: A Recent Approach for Novel Drug delivery Reddy PK, Putta SK, Deepthi PN OP

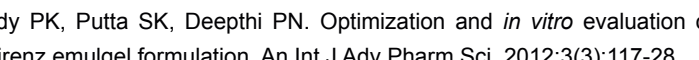

12. Ghodekar SV, Chaudhari SP, Ratnaparakhi MP. Development a characterization of siver sulfadizine emulgel for topical drug delivery. Int $\lrcorner$

Kumar KJR, Muralidhharan S, Dhanaraj SA. Antitingal activity of
microemulsion based fuconazole gel for onychomycosis against Aspergillus Niger. Int J Pharm Pharm Sci. 2012:5(1):3-9.

STavan WN, Vamma K, Maheshwari PV etal. Calcipotriol delivery into the skin a

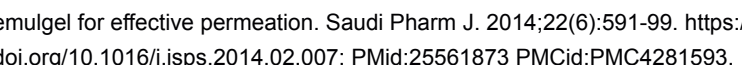

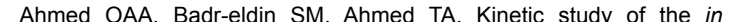
release and stability of Theophylline floating beads. Int $J$ Pharm Pharm Sci 2013:5(1):1-6.

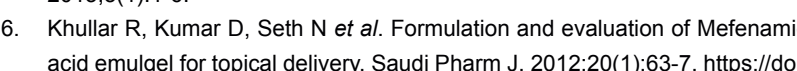

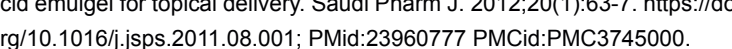
Bhandari N, Verma P, Sing H. Proniosomes: A surrogate for Transderma drug delivery. Int J Pharms Res \& Bio Sci. 2012; ; 1:10-26.

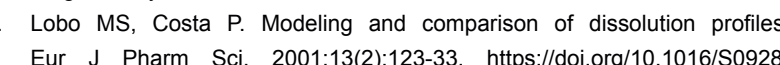
0987(01)00095-1.

19. Ahmed OAA, Badr-eldin SM, Ahmed TA. Kinetic study of the in vitro release
and stability of Theophylline floating beads. Int J Pharm Pharm Sci. 2013;5:1-6.

\section{SUMMARY}

- Tapentadol is an opioid analgesic. Tapentadol is indicated for the treatment of Moderate to severe pain for both acute (following injury, surgery, etc.) and chronic musculoskeletal pain. Tapentadol has poor an oral bioavailability of $31.9 \pm 6.8 \%$ and it causes gastric side effects such as nausea, vomiting, stomach discomfort.

- The emulgel formulation contains combinations of emulsion and gel. The emulsion is a very good vehicle for the delivery of hydrophobic drug but it is thermodynamically unstable. The emulsion when incorporated into the gel increases the stability of emulsion. The emulgel is a dual control release system. The emulgel being thixotropic, greaseless, spreads easily nonstaining so it offers a better patient compliance.

Preformulation studies were performed on the drug and excipients. The FTIR analysis revealed that the drug and for the construction of pseudoternary phase diagrams and emulsion was prepared based on the saturation solubility results.

- The pseudoternary phase diagram showed that the surfactant: co-surfactant ratio 1:1 showed minimum microemulsion area but 3:1 ratio showed the maximum microemulsion area. The prepared emulsions were evaluated for drug content and globule size and the results showed that PI and $Q 1$ formulation were selected as optimized formulation

optimized emulsion formulations were then incorporated into the gel base to give the emulgel by varying the gelling agent concentration i.e. $1.5 \%$ and $2 \%$. The prepared emulgel formulations were evaluated for percent drug content, $\mathrm{pH}$, viscosity, spreadability, extrudability and percentage cumulative drug release.

- The optimized formulation was subjected to skin irritation test and no irritation was observed on the wistar rat's skin so the formulation can be considered as safe for use. The ex vivo study was conducted using

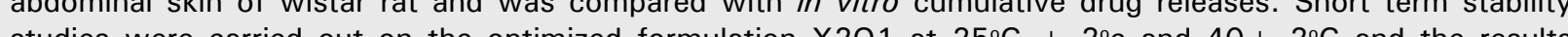
showed physicochemical stability.

Based on the drug content, viscosity, spreadability, percentage cumulative drug release Tapentadol can be considered as an ideal candidate for the formulation of emulgel.

\section{About Authors}

2 $\Rightarrow$ Paresh Mandora: Obtained His post-graduate in 2016 from Dept. of Pharmaceutics, Faculty of - Pharmacy, KLE University, Belagavi. He worked in the area of Topical formulations carrier to I. improve the drug permeation across skin.

2 Panchaxari Mallappa Dandagi: Is a Professor, Department of Pharmaceutics, Faculty of Pharmacy, KLE University, Belagavi. He is working on ar, Deas of targeted drug delvery system viz, Colon dug delivery system us
and microspheres.

Anand Panchakshari Gadad: Is a Professor and Head, Department of Pharmaceutics, Faculty of Pharmacy, KLE University, Belagavi. He is working on areas of targeted drug delivery system soluble drugs, etc
siz., Gastroretentive

Nitin Prabhakar Ambhore: Is a Research Scholar, Department of Pharmaceutics, Faculty of improve the bioavailability Cite this article: Mandora P, Dandagi PM, Gadad AP, Ambhore NP. Formulation and Characterization of Tapentadol
Loaded Emulgel for Topical Application. Indian J of Pharmaceutical Education and Research. 2017;51(4):525-35. 